\title{
Keratoconus treatment using femtosecond- assisted intrastromal corneal graft (FAISCG) surgery: a case series
}

This article was published in the following Dove Press journal: International Medical Case Reports Journal

\author{
Khosrow Jadidi' \\ Seyed Aliasghar Mosavi² \\ 'Department of Ophthalmology, \\ Baqiyatallah University of Medical \\ Sciences, Tehran, Iran; ${ }^{2}$ Vision Health \\ Research Center, Tehran, Iran
}

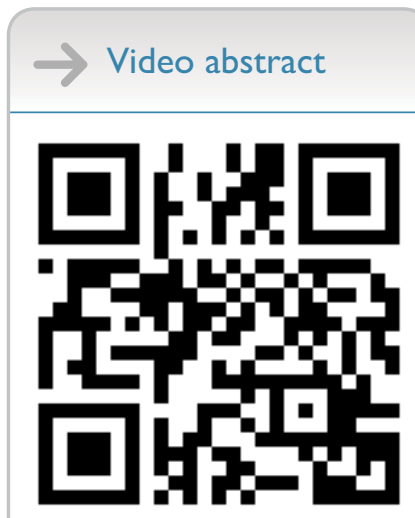

Point your SmartPhone at the code above. If you have a $Q R$ code reader the video abstract will appear. Or use: http://youtu.be/FT7Dm_F0ej0
Correspondence: Khosrow Jadidi Department of Ophthalmology, Baqiyatallah University of Medical Sciences, Tehran I43487338I, Iran Tel +9821 88785273

Email khosrow.jadidi@yahoo.com

\begin{abstract}
We describe an intrastromal corneal graft technique that uses femtosecond laser to create a desirable corneal lenticule with precise diameter, depth, and shape as well as an intrastromal pocket in keratoconus patients. The technique seems to be a feasible and safe treatment option to treat keratoconic eyes with reference to the irregularity and instability of cornea. The technique can be performed easily and appears safe and effective. At 7 days postoperatively, all eyes were white and quiet, and the grafts were clear. No graft folds or interface complications were observed at the 12-month follow-up using Visante optical coherence tomography.
\end{abstract}

Keywords: keratoconus, femtosecond assisted, intrastromal, corneal graft

\section{Introduction}

Keratoconus is a bilateral, progressive, noninflammatory disease of cornea which often leads to high myopia and astigmatism with an estimated prevalence of approximately 1 in $2000,{ }^{1}$ although it may be much higher in other areas. ${ }^{2}$

Keratoconus seems to be a multifactorial disease with unknown exact etiology. However, biomechanical instability is thought to be one of the main causes. ${ }^{3}$

According to disease severity, many modalities exist for the treatment of keratoconus, including glasses, contact lenses, and intrastromal ring for mild-to-moderate disease. ${ }^{1,4,5}$ Several authors believe that adding volume to the peripheral cornea by implanting ring segments may reduce central corneal steepening in keratoconus. ${ }^{6,7}$ However, some complications were detected in previous studies. ${ }^{8}$ Additionally, a highly irregular shape of the cornea in advanced keratoconus still remains a main problem. Therefore, corneal graft as an option was preserved for more advanced disease. ${ }^{9}$

The presented technique was planned to fulfill the centralization easily, optimizing the optical properties, and to save the biomechanics of the cornea. So far as we know, this is the first report that demonstrates the effect of the positioning of a corneal intrastromal graft on the irregularity, instability, and refractive results of cornea using femtosecond laser.

\section{Case reports}

\section{Surgical technique}

The surgical procedures were performed at Basir Hospital, Tehran, Iran, and approved by the ethics committee. Four consecutive patients (men) were enrolled for the series. Written informed consent was obtained in all cases. The surgical femtosecond assisted 
intrastromal corneal graft (FAISCG) technique shown in the Video $\mathrm{S} 1$ is characterized by three-step procedure as follows:

\section{Step I: Creation of a corneal lenticule in donor eye}

Preoperatively, epitheliums of donor eyes from the whole globe were removed with a blade number 15 . Subsequently, a desirable corneal lenticule with precise diameter, depth, and shape was created using Ziemer LDV femtosecond laser (Ziemer AG, Port, Switzerland). To create the donor grafts, corneoscleral donor tissue was removed from storage solution (Optisol-GS; Bausch and Lomb Surgical, Irvine, CA, USA) and mounted on an artificial anterior chamber (LDV; Ziemer Ophthalmic Systems AG). The femtosecond laser keratoplasty software was programmed as follows: a donor lenticule thickness of 140-250 mm, applanation 7-9 mm, vacuum value 700 mbar, total cut in donor tissue 45 seconds, and an applanation time ranging from 10 to 20 seconds in the patients and donors. For donors and patients, we used $4.0 \mathrm{~mm} / \mathrm{s}$ velocity of the stroma and $30 \mathrm{~mm} / \mathrm{s}$ velocity of the border.

The proper depth of the cornea was defined by subtracting the normal corneal depth measure from the thinnest part of the recipient cornea. The shape of the lenticule was determined on the basis of keratoconus types; in central keratoconus, circular shape was chosen; in inferior keratoconus, crescent shape was chosen; and in asymmetric bow-tie keratoconus, mesopic pupil size and round shape were selected (Video S1) (Figure S1). In addition, the accurate diameter measurement was based on lenticule size.

\section{Step 2: Creation of a corneal pocket in recipient eye}

The intracorneal pocket entry in recipient eye was created on the steepest corneal topographic axis using femtosecond surgical laser. The pocket depth was set at 250 micron of the corneal thickness at the incision site. Then, the intracorneal pockets were gently separated from the underlying stroma using a Sinskey hook and a spatula.

\section{Step 3: Graft implantation}

After creation of the intrastromal pocket via the small incision while the pocket was easily opened using a dissecting spatula, an intrastromal corneal graft was implanted immediately into the corneal pocket. The graft implantation into the pocket is easily achievable. The implantation procedure and adjustment of the graft in the pocket can be performed by a Sinskey hook

Table I Patient characteristics and outcomes

\begin{tabular}{|c|c|c|c|c|}
\hline Characteristic & Patient I & Patient 2 & Patient 3 & Patient 4 \\
\hline \multicolumn{5}{|l|}{ Demographics } \\
\hline Sex & Male & Male & Male & Male \\
\hline Age, years & 29 & 28 & 23 & 29 \\
\hline Eye & OD & OS & OD & OS \\
\hline Diagnosis & Keratoconus & Keratoconus & Keratoconus & Keratoconus \\
\hline \multicolumn{5}{|l|}{ UCVA } \\
\hline Preoperative & $4 / 10$ & $4 / 10$ & $5 / 100$ & $4 / 10$ \\
\hline 3 months postoperative & $5 / 10$ & $5 / 10$ & $3 / 10$ & $3 / 10$ \\
\hline 6 months postoperative & $6 / 10$ & $8 / 10$ & $5 / 10$ & $2 / 10$ \\
\hline 12 months postoperative & $7 / 10$ & $9 / 10$ & $5 / 10$ & $6 / 10$ \\
\hline Preoperative refraction & $S-4.00 \mathrm{C}-3 \times 20$ & $C-5 \times 170$ & S-3 C-4×50 & S-4.5 C-2.5×II7 \\
\hline 3 months postoperative & S-3.00 C- $2.5 \times 115$ & S-I C $-3 \times 165$ & S-4 C- $5 \times 35$ & S-2.5 C- $3 \times 125$ \\
\hline 6 months postoperative & $\mathrm{S}-2.50 \mathrm{C}-2 \times 115$ & S-I C- $2 \times 170$ & $S-3 C-5 \times 10$ & S- $2.5 C-3 \times 125$ \\
\hline 12 months postoperative & S- $1.00 \mathrm{C}-2 \times 90$ & S- 0.5 C- $2 \times 165$ & $S-3 C-4 \times 5$ & $S-3 \mathrm{C}-2 \times 119$ \\
\hline \multicolumn{5}{|c|}{ Lines gained of UCVA from preoperation } \\
\hline I month postoperative & 3 & 5 & 7 & 2 \\
\hline \multicolumn{5}{|l|}{$\mathrm{Kmax}(\mathrm{D})$} \\
\hline Preoperative & 42.1 & 48.8 & 55.8 & 43.6 \\
\hline 12 months postoperative & 42 & 47.5 & 53.1 & 44.2 \\
\hline \multicolumn{5}{|l|}{ Kmin $(D)$} \\
\hline Preoperative & 40 & 42.5 & 50.9 & 42.1 \\
\hline 12 months postoperative & 41.4 & 43.2 & 46.7 & 43 \\
\hline \multicolumn{5}{|l|}{ Kmean (D) } \\
\hline Preoperative & 41.5 & 45.3 & 50.8 & 42.8 \\
\hline 12 months postoperative & 42 & 45.2 & 46.6 & 43.6 \\
\hline \multicolumn{5}{|l|}{ Clinical examination } \\
\hline Slit-lamp at I month & Clear graft & Clear graft & Clear graft & Clear graft \\
\hline Topographic patterns & Regular astigmatism & Regular astigmatism & Regular astigmatism & Regular astigmatism \\
\hline
\end{tabular}

Abbreviations: Kmax, maximum K-value in diopters; Kmean, average K-value in diopters; Kmin, minimum K-value in diopters; UCVA, uncorrected visual acuity. 
or forceps. The incision site is self-sealing and does not require suturing. The procedure takes approximately 30 minutes. Subsequently, a silicone-hydrogel bandage contact lens (Bausch and Lomb, Alcon Laboratories, Inc., Fort Worth, TX, USA) was placed on the cornea. Postoperatively, patients were given betamethasone drops (Sina Darou, Tehran, Iran) four times a day, chloramphenicol drops (Sina Darou) six times a day, and nonpreserved artificial tears (Artelac Advanced) (Baush and Lomb, Rochester, NY USA) six times daily. Chloramphenicol drops were discontinued 7 days postoperatively and betamethasone drops tapered off in 4 weeks. Bandage contact lenses were removed 1 day postoperation. Patients were scheduled for postoperative clinical examination on the $1 \mathrm{st}$ day, $1 \mathrm{st}$ week, and afterward in the $1 \mathrm{st}$, 3rd, and 6th month, and yearly.

\section{Clinical data}

The characteristics of patients included in this case series are summarized in Table 1. No intraoperative and postoperative complications occurred. At 7 days postoperatively, all eyes were white and quiet, and the grafts were clear (Figures S2-S5).

Figure S2A is a 7 days postoperative slit lamp photograph of the right eye of a 29-year-old man who was treated with a refraction of $-4.00-3 \times 20$ (left image). The uncorrected visual acuity (UCVA) was $4 / 10$. The preoperative topography is shown in Figure S2B (middle image). The maximum K-value was 42.1 diopters (D) and the central K-values were 41.5 $\mathrm{D}$ at the steepest and $40 \mathrm{D}$ at the flattest meridian. Corneal thickness at the thinnest point was $377 \mu \mathrm{m}$.

The mesopic pupil size was $3.5 \mathrm{~mm}$. Twelve months after implantation of the graft ( $7 \mathrm{~mm}$ diameter and $140 \mu \mathrm{m}$ thickness) centered at the corneal reflex, UCVA was $7 / 10$ with a refraction of $-1.00-2.00 \times 90$. The topography is shown in Figure S2C (right image).

Figure S3A shows the left eye of a 28-year-old man 7 days after implantation of graft. While the preoperative refraction was $-5 \times 170$, postoperatively it was $-0.5-2 \times 165$. Twelve months postoperatively, the UCVA was 5 lines bet-
A

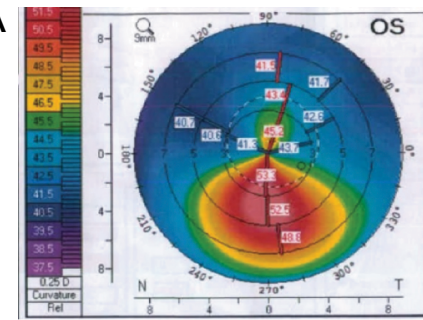

B

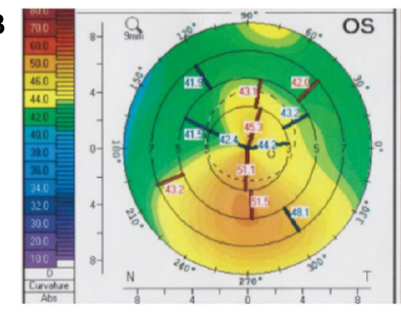

C

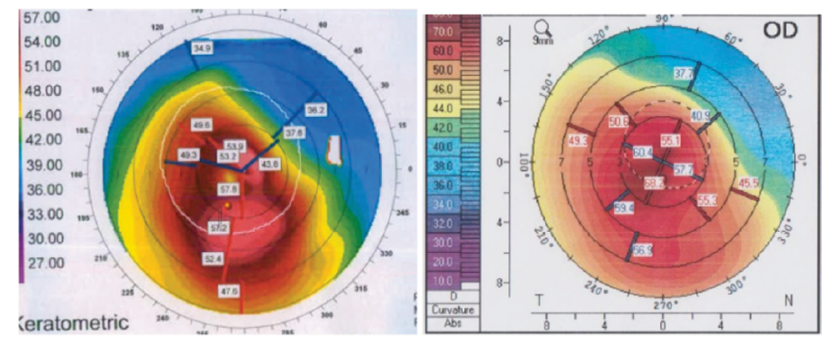

D

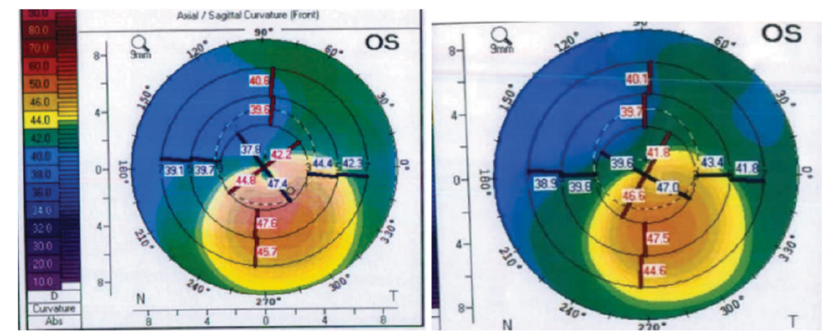

Figure I Preoperative (left), and postoperative topographies (right) after femtosecond-assisted intrastromal corneal graft surgery (A-D) showing a kind of "regularization" of the corneal surface postoperatively in study cases I-4. 
ter than the UCVA before surgery. The changes in corneal topography (Figure S3B-C) demonstrate that cylinder of up to at least $3.0 \mathrm{D}$ can be corrected. They also demonstrate a kind of "regularization" of the corneal surface.

Figure S4A shows a graft in situ in the right eye of a 23-year-old man 1 month after implantation. Cosmetically, the implant appears similar to a normal cornea. The preoperative refraction was $-3-4 \times 50$. The uncorrected visual acuity was $5 / 100$. One week postoperatively, the eye was emmetropic and the uncorrected visual acuity was 7 lines better than the uncorrected visual acuity before surgery. Figure S4(B-C) shows the corneal topography before surgery (middle), and 12 months after surgery (right). No graft folds or interface complications were observed in the postoperative course. The patient is very satisfied and has not reported daytime or night time problems.

Figure S5A shows the left eye of a 29-year-old man 7 days after implantation of graft. While the preoperative refraction was $-4.5-2.5 \times 117$, postoperatively it was $-3-2 \times 119$. Twelve months postoperatively, the uncorrected visual acuity was 2 lines better than the uncorrected visual acuity before surgery. Increased corneal thickness was observed with optical slit scanning topography in the area along with no graft folds or interface complications postoperatively (Figure S6). They also demonstrated a kind of "regularization" of the corneal surface postoperatively (Figure 1). Ocular Response Analyzer measurement was done for study cases (data not shown here) which showed that no significant changes were detected in corneal hysteresis and corneal resistance factor after graft implantation (Figure S7).

\section{Discussion}

A high grade of safety and efficacy was demonstrated by adding volume to the corneal periphery for myopia correction. ${ }^{6,7}$. However, a highly irregular shape of the cornea in advanced keratoconus remains a major problem.

The femtosecond laser technology that was commercially introduced in the year 2002 for creation of a corneal flap in laser in-situ keratomileusis allows a new type of intrastromal lamellar keratoplasty with removal of a mid-stromal segment for both donor and recipient corneas in animal studies. ${ }^{10}$ However, to the best of our knowledge, no report has been published regarding femtosecond-assisted intrastromal cornea graft in humans so far.

Our clinical data show that this technique enables correcting irregularity as well as instability and refractive errors. In this study, we made a corneal punch into the required shape and reimplanted the reshaped layer into the eye, similar to the Jose Barraquer ${ }^{11}$ technique. However, a femtosecond laser was used in our technique, which made it different from Barraquer's procedure.

Moreover, the geometry of the corneal surface improved into a generally regular shape. Consequently, sources of higher-order aberrations were somehow eliminated, triggering correction of refractive errors. We believe that using normal corneal tissue may possibly terminate the side effects of corneal ring implantation, holding back the need for corneal grafting and improving the quality of life.

In summary, this technique is easy to perform and appears to be safe and effective, particularly for the treatment of irregularly shaped corneas such as in keratoconus. However, because of the progressive characteristics of keratoconus disease, it remains unclear whether this technique is able to control the progression of the disease. Therefore, we suggest cornea cross-linking as an approach to halt the progression of corneal ectatic disorders along with intrastromal corneal graft. Moreover, further investigations and case series analysis and long-term follow-up are required to confirm our finding.

\section{Disclosure}

The authors report no conflicts of interest in this work.

\section{References}

1. Rabinowitz YS. Keratoconus. Surv Ophthalmol. 1998;42:297-319.

2. Gomes JA, Tan D, Rapuano CJ, et al. Global consensus on keratoconus and ectatic diseases. Cornea. 2015;4:359-369.

3. Daxer A, Fratzl P. Collagen fibril orientation in the human corneal stroma and its implication in keratoconus. Invest Ophthalmol Vis Sci. 1997;38:121-129.

4. Weed KH, MacEwen CJ, Giles T, Low J, Mc Ghee CN. The Dundee University Scottish Keratoconus study: demographics, corneal signs, associated diseases, and eye rubbing. Eye. 2008;22:534-541.

5. Bilgin LK, Yilmaz S, Araz B, Yüksel SB, Sezen T. 30 years of contact lens prescribing for keratoconic patients in Turkey. Cont Lens Anterior Eye. 2006;32:16-21.

6. Ertan A, Colin J. Intracorneal rings for keratoconus and keratectasia. J Cataract Refract Surg. 2007;33:1303-1314.

7. Miranda D, Sartori M, Francesconi C, Allemann N, Ferrara P, Campos M. Ferrara intrastromal corneal ring segments for severe keratoconus. $J$ Refract Surg. 2003;19:645-653.

8. Jadidi K, Mosavi SA, Nejat F, Alishiri A. Complications of intrastromal corneal ring implantation (Keraring 355) using a femtosecond laser for channel creation. Int J Kerat Ectatic Corneal Dis. 2014;3(2):53.

9. Funnell CL, Ball J, Noble BA. Comparative cohort study of the outcomes of deep lamellar keratoplasty and penetrating keratoplasty for keratoconus. Eye (Lond). 2006;20:527-532.

10. Jonas JB. Intrastromal lamellar femtosecond laser keratoplasty with superficial flap. Br J Ophthalmol. 2003;87(9):1195.

11. Barraquer JI. The history and evolution of keratomileusis. Int Ophthalmol Clin. 1996;36(4):1-7. 


\section{Supplementary material}
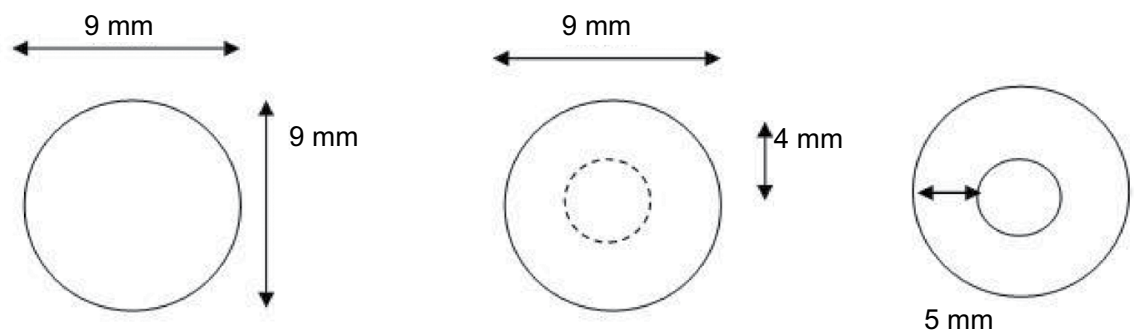

Figure SI Schematic drawing of the process of creating a round cut using a circular punch biopsy device (from left to right).

Notes: The tip of the blade is guided along a curved path (interrupted line) to cut a round lenticule (full line).
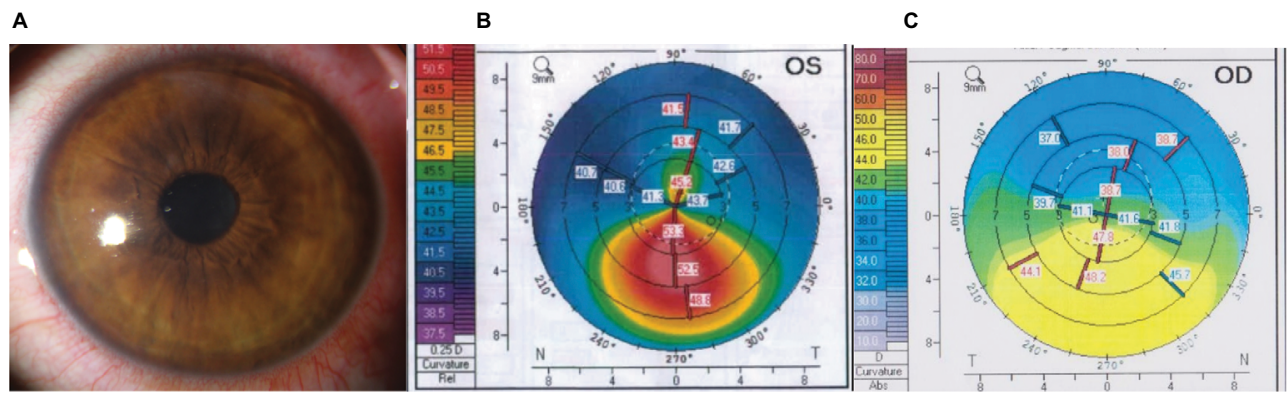

Figure S2 (A) Slit-lamp photograph 7 days after graft implantation, (B) Corneal topography before graft implantation (middle), (C) 12 months postoperatively (right).

A
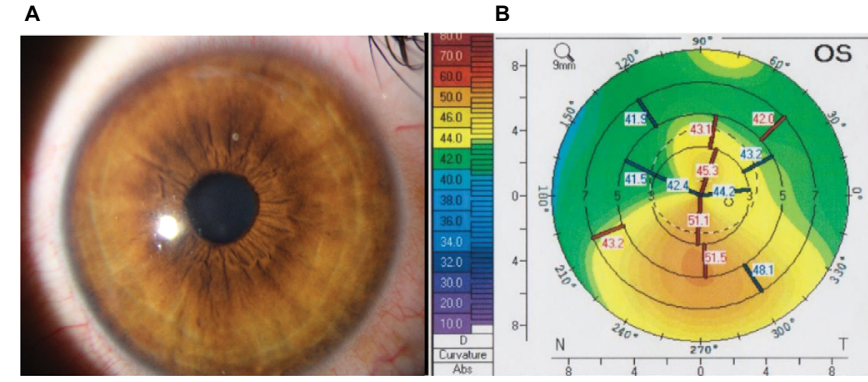

C

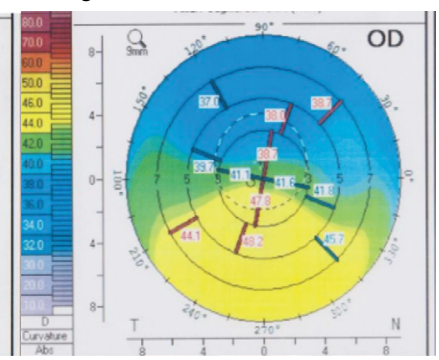

Figure S3 (A) Slit-lamp photograph 7 days after graft implantation, (B) Corneal topography before graft implantation (middle), (C) 12 months postoperatively (right). 
A

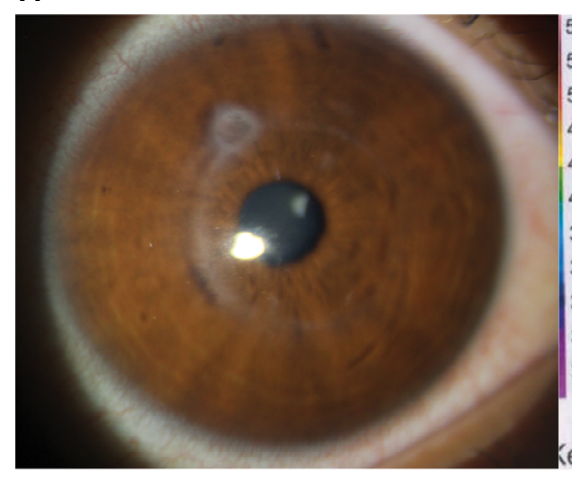

B

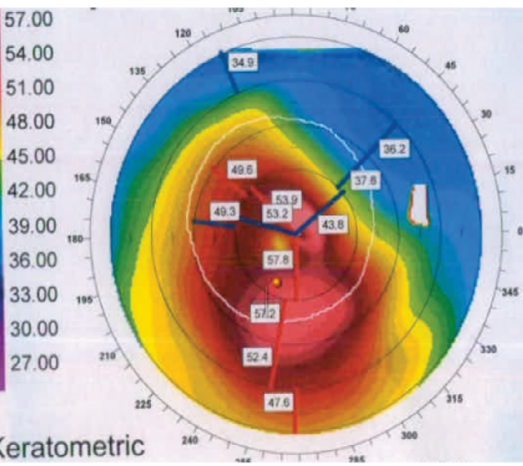

C

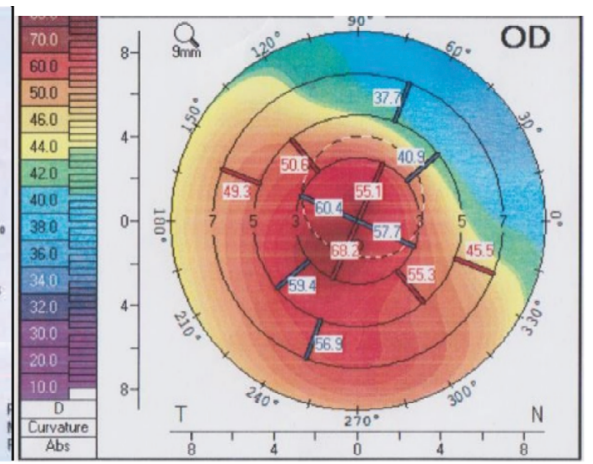

Figure S4 (A) Slit-lamp photograph showing superior paracentral scar where the implant was placed at ring removal area and a graft in situ in the right eye of a 23 -year-old man 7 days after graft implantation, (B) Corneal topography before graft implantation (middle), (C) 12 months postoperatively (right).
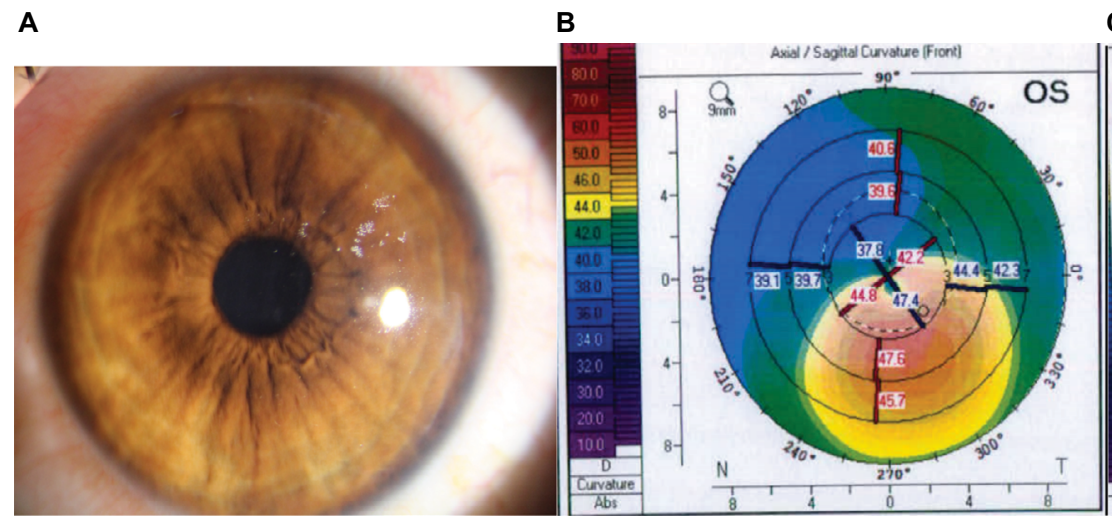

C

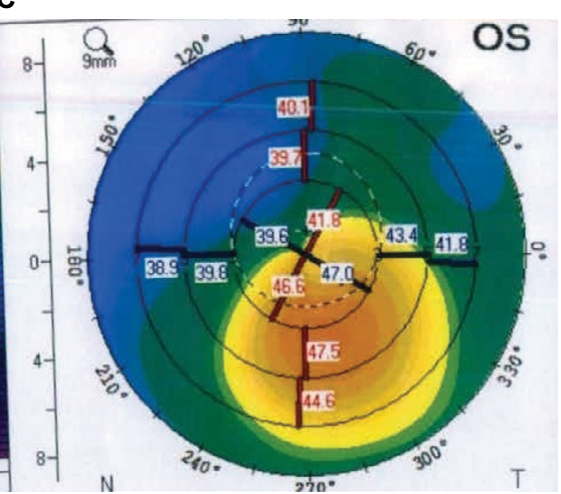

Figure S5 (A) Slit-lamp photograph 7 days after graft implantation, (B) Corneal topography before graft implantation (middle), (C) 12 months postoperatively (right).
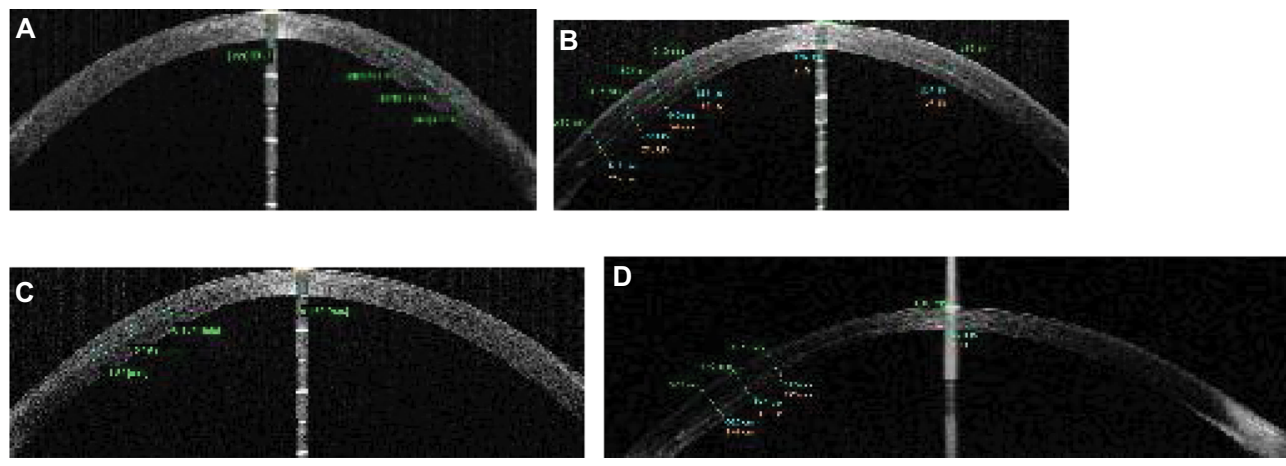

Figure S6 Visante optical coherence tomography cut of study cases (A-D) through the cornea 12 months after graft implantation. 
A
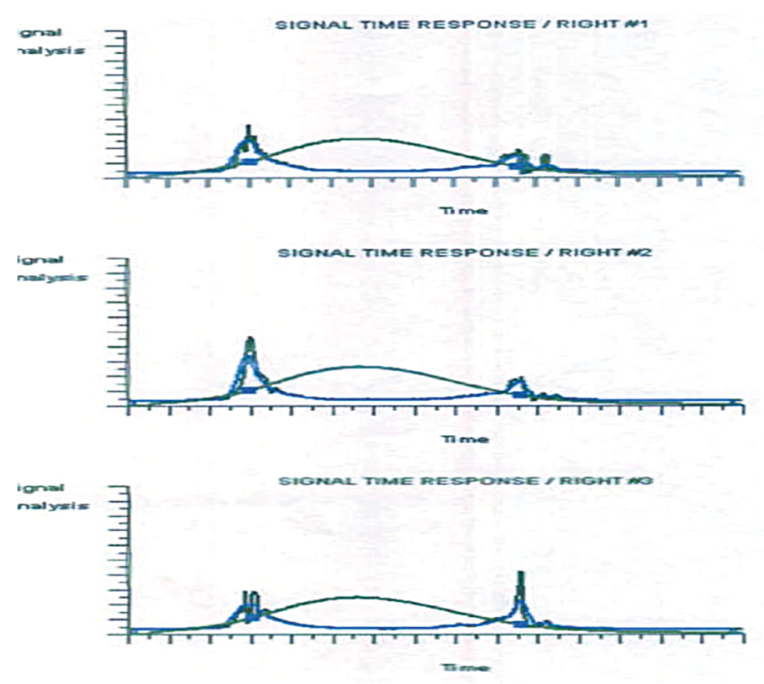

B

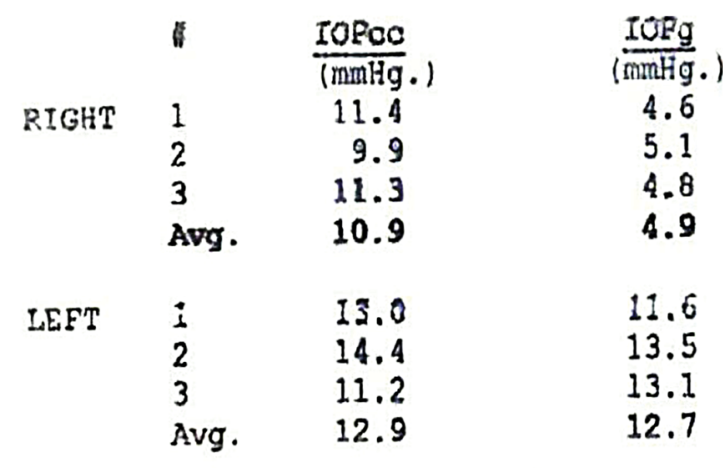

C

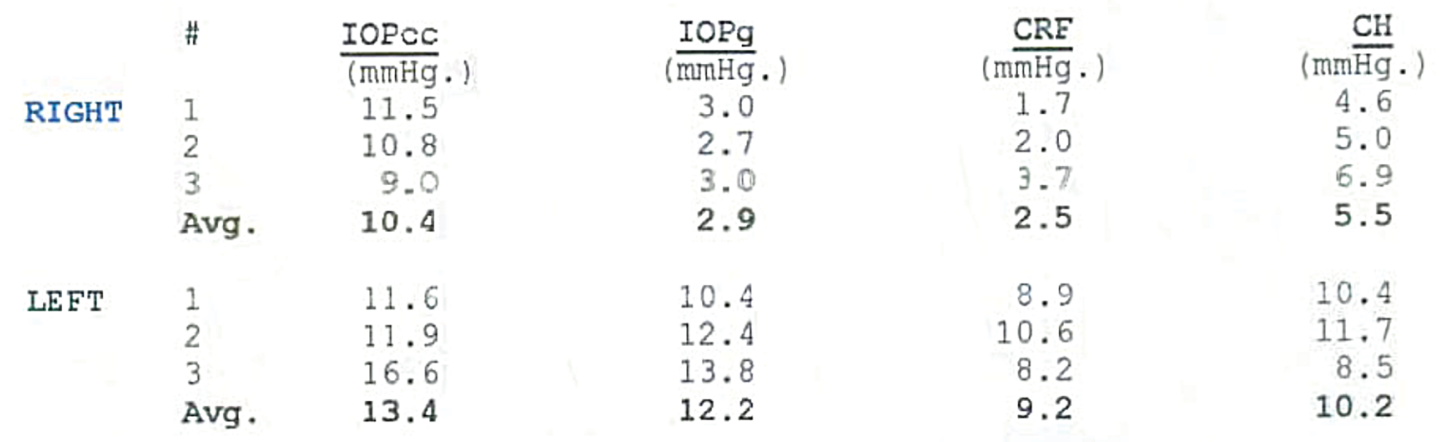

Figure S7 (A-C) Typical Ocular Response Analyzer signal, before and 5 months after graft implantation from a cornea in the right eye of a 23 -year-old man. Abbreviations: IOP, intraocular pressure; $\mathrm{CRF}$, corneal hysteresis; $\mathrm{CH}$, corneal resistance factor.

International Medical Case Reports Journal

\section{Publish your work in this journal}

The International Medical Case Reports Journal is an international, peer-reviewed open-access journal publishing original case reports from all medical specialties. Previously unpublished medical posters are also accepted relating to any area of clinical or preclinical science. Submissions should not normally exceed 2,000 words or

Submit your manuscript here: https://www.dovepress.com/international-medical-case-reports-journal-journal
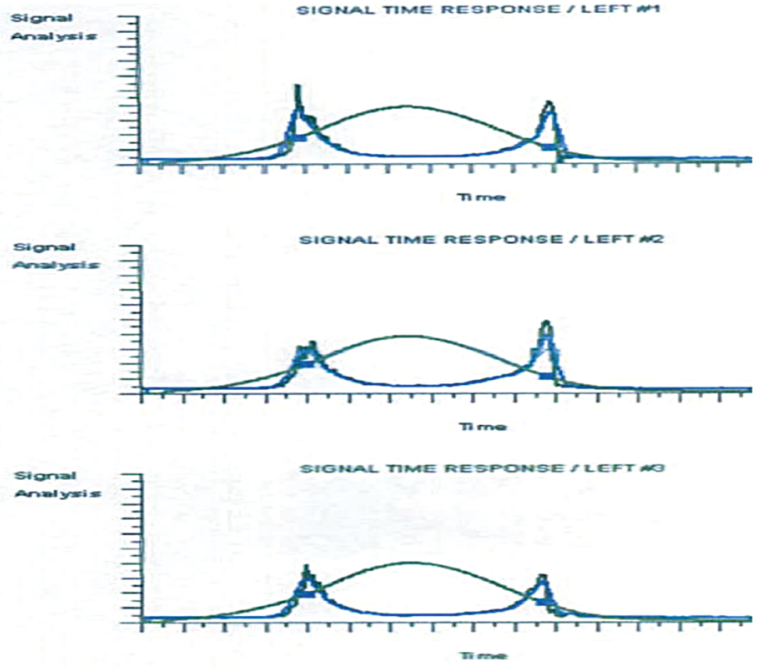

$\begin{array}{cc}\frac{\mathrm{CKn}}{(\mathrm{mmHg} .)} & \begin{array}{c}\mathrm{mis} \\ 3.3\end{array} \\ 5.0 & 5.9 \\ 3.7 & 7.7 \\ 4.0 & 6.3 \\ & 6.6 \\ 8.9 & 10.0 \\ 9.7 & 10.3 \\ 11.8 & 12.9 \\ 10.1 & 11.1\end{array}$

4 published pages including figures, diagrams and references. The manuscript management system is completely online and includes a very quick and fair peer-review system, which is all easy to use. Visit http://www.dovepress.com/testimonials.php to read real quotes from published authors. 